\title{
Correction to: Performance of novel non-invasive urine assay UroSEEK in cohorts of equivocal urine cytology
}

\author{
Maria Del Carmen Rodriguez Pena ${ }^{1,2} \cdot$ Simeon U. Springer ${ }^{3,4} \cdot$ Diana Taheri ${ }^{2,5} \cdot \mathrm{Lu} \mathrm{Li}^{3,4} \cdot$ Aline C. Tregnago $^{2}$. \\ Marie-Lisa Eich ${ }^{1,2}$. Isam-Eldin A. Eltoum ${ }^{1}$. Christopher J. VandenBussche ${ }^{2}$. Nickolas Papadopoulos ${ }^{3,4}$. \\ Kenneth W. Kinzler ${ }^{3,4} \cdot$ Bert Vogelstein ${ }^{3,4} \cdot$ George J. Netto ${ }^{1,2}$ (i)
}

Published online: 18 February 2022

○) Springer-Verlag GmbH Germany, part of Springer Nature 2022

\section{Correction to: Virchows Archiv (2019) 476:423-429 \\ https://doi.org/10.1007/s00428-019-02654-1}

In the Funding information of the original published version of the above article, the grant number P30 CA077598 has been removed. The Funding statement has been updated as follows:

Funding information Support provided by Henry and Marsha Laufer, Virginia and D.K. Ludwig Fund for Cancer Research, the Commonwealth Foundation, John Templeton Foundation, Conrad R.

Hilton Foundation and grants from the NIH (T32 GM007309/GM/NIGMS NIH HHS/United States;
P30 CA006973/CA/NCI NIH HHS/United States; R01 ES019564/ES/NIEHS NIH HHS/United States). All sequencing was performed at the Sol Goldman Sequencing Facility at Johns Hopkins.

The original article has been corrected.

Publisher's note Springer Nature remains neutral with regard to jurisdictional claims in published maps and institutional affiliations.

The original article can be found online at https://doi.org/10.1007/ s00428-019-02654-1.

\section{George J. Netto}

gnetto@uabmc.edu

1 Department of Pathology, The University of Alabama at Birmingham, Birmingham, AL 35233, USA

2 Department of Pathology, The Johns Hopkins Hospital, Baltimore, MD 21231, USA

3 The Ludwig Center for Cancer Genetics and Therapeutics, Baltimore, MD 21231, USA

4 Sidney Kimmel Comprehensive Cancer Center, Baltimore, MD 21231, USA

5 Department of Pathology, Isfahan Kidney Diseases Research Center, Isfahan University of Medical Sciences, Isfahan, Iran 